\title{
Upregulation of Platelet-derived Growth Factor-A and -B Gene Expression in Alveolar Macrophages of Individuals with Idiopathic Pulmonary Fibrosis
}

\author{
I. Nagaoka, B. C. Trapnell, and R. G. Crystal \\ Pulmonary Branch, National Heart, Lung, and Blood Institute, National Institutes of Health, Bethesda, Maryland 20892
}

\begin{abstract}
Idiopathic pulmonary fibrosis (IPF) is characterized by accumulation of alveolar macrophages spontaneously releasing exaggerated amounts of the potent mesenchymal cell growth factor platelet-derived growth factor (PDGF). To evaluate the relative contribution of the two PDGF genes to this process, PDGF-A and -B gene transcription rates and mRNA levels were examined in normal and IPF alveolar macrophages. While normal alveolar macrophages constitutively transcribe both PDGF-A and PDGF-B genes, LPS stimulation increases the transcription of both genes more than threefold. Importantly, IPF alveolar macrophages spontaneously transcribe both genes at a rate similar to that observed for normal macrophages after in vitro stimulation. Consistent with the transcription data, normal macrophages contain mRNA for both PDGF-A and -B, but PDGF-B mRNA is 10-fold more abundant. Strikingly, in IPF, both PDGF-A and -B mRNA levels were markedly increased, with persistence of the 10-fold dominance of PDGF-B mRNA. Thus, the exaggerated release of PDGF by IPF alveolar macrophages is likely modulated by upregulated PDGF gene transcription rates and concomitantly increased mRNA levels and the persistent 10-fold excess of $B$ $>$ A PDGF mRNA suggests that the PDGF released by alveolar macrophages is likely mostly of the potent B-chain homodimeric form. (J. Clin. Invest. 1990. 85:2023-2027.) PDGF • fibrosis • lung • macrophage $\bullet$ transcription • gene regulation
\end{abstract}

\section{Introduction}

Alveolar macrophages, pulmonary representatives of the mononuclear phagocyte system of bone marrow-derived cells, play a central role in normal wound healing and pathogenic fibrosis by virtue of their ability to release a variety of inflammatory mesenchymal cell chemoattractants and polypeptide growth factors (1-4). The most potent of these polypeptides is platelet-derived growth factor (PDGF), ${ }^{1}$ a $30-\mathrm{kD}$ dimer of two disulfide-linked polypeptides (5-7). In addition to serving as a potent mitogen that stimulates mesenchymal cells to enter and

Address reprint requests to Dr. Crystal, Pulmonary Branch, Building 10, Room 6D03, National Institutes of Health, Bethesda, MD 20892.

Received for publication 25 September 1989 and in revised form 27 February 1990.

1. Abbreviations used in this paper: IPF, idiopathic pulmonary fibrosis; PDGF, platelet-derived growth factor.

The Journal of Clinical Investigation, Inc.

Volume 85, June 1990, 2023-2027 proceed through the early $\mathrm{G} 1$ phase of the growth cycle, PDGF can modulate cell motility, including chemotaxis (5-7). Recent studies have demonstrated that human alveolar macrophages from the lungs of individuals with idiopathic pulmonary fibrosis (IPF), a chronic, fatal lung disorder characterized by diffuse fibrosis of the alveolar walls, spontaneously release exaggerated amounts of PDGF compared with macrophages from normal individuals. This suggests that PDGF released by alveolar macrophages in the lower respiratory tract is important in the pathogenesis of pulmonary fibrosis by modulating the accumulation of mesenchymal cells in the alveolar walls (8).

There are two human PDGF genes, denoted A and B. PDGF-A is a seven exon gene spanning $24 \mathrm{~kb}$ on chromosome 7 at p21-p22 $(9,10)$. The A chain polypeptide occurs in two variants resulting from alternative splicing of exon VI; the resulting 23-kD precursor proteins differ in size by 15 amino acids $(11,12)$. PDGF-B is also a seven exon gene of $24 \mathrm{~kb}$, but is located on chromosome 22 at q12.3-q13.1 and codes for a single 27-kD precursor protein (13-15). The PDGF-B gene is also known as the $c$-sis protooncogene, a normal cellular gene with close homology to the $v$-sis transforming gene of the simian sarcoma virus that exerts its transforming properties by directing the target cells to produce a potent mitogen abundantly in an autocrine fashion, thus subverting the normal control of mesenchymal cell growth in which the growth stimuli are external to the cell and are rate limiting (16-18). In regard to alveolar macrophages and IPF, qualitative analysis has demonstrated that normal and IPF alveolar macrophages contain PDGF-B mRNA transcripts (19), but it is not known whether alveolar macrophages are capable of expressing the PDGF-A gene. Further, while IPF alveolar macrophages are spontaneously releasing exaggerated amounts of PDGF (8), it is not known if this is associated with an upregulation of expression of the PDGF gene(s).

In the context of the likely importance of alveolar macrophage PDGF gene expression in the pathogenesis of IPF, the present study was designed to evaluate the regulation of PDGF gene expression in alveolar macrophages from normals and individuals with IPF. To accomplish this, we have evaluated transcription rates and mRNA levels for both PDGF-A and -B genes in alveolar macrophages from both groups.

\section{Methods}

Study population. The diagnosis of IPF was established in 10 individuals $(9$ males, 1 female; mean age $52 \pm 4$ yr, 7 nonsmokers or exsmokers [ $>2 \mathrm{yr}$ ], 3 current smokers) in mid-course by previously described criteria including clinical history, physical examination, chest roentgenography, lung function tests (vital capacity, $76 \pm 4 \%$ pre- 
dicted; total lung capacity, $77 \pm 6 \%$ predicted; forced expiratory volume in $1 \mathrm{~s} /$ forced vital capacity, $114 \pm 4 \%$ predicted; carbon monoxide diffusion capacity [corrected for lung volume and hemoglobin], $49 \pm 6 \%$ predicted), and open lung biopsy $(1,20)$. Seven were untreated, one was receiving prednisone $(20 \mathrm{mg} / \mathrm{d})$, and two were receiving cyclophosphamide ( 50 and $100 \mathrm{mg} / \mathrm{d}$, respectively). Normals included eight nonsmoking individuals ( 5 males, 3 females; mean age, $38 \pm 4 \mathrm{yr}$ ) with no history of lung disease. All had normal physical examination, chest roentgenograms and lung physiology. All data are presented as mean \pm SEM; statistical comparisons were made using the two-tailed Student's $t$ test.

Isolation of alveolar macrophages. Alveolar macrophages were recovered by bronchoalveolar lavage as previously described (21). Total cell populations recovered from individuals with IPF were typical of the disorder (22), characterized by an increased number of cells recovered $\left(81 \pm 15 \times 10^{6}\right.$ compared to $31 \pm 4 \times 10^{6}$ for the normals), with a relatively increased proportion of neutrophils (IPF $89 \pm 1 \%$ macrophages, $3 \pm 1 \%$ lymphocytes, $6 \pm 1 \%$ neutrophils, $2 \pm 1 \%$ eosinophils; normal $90 \pm 1 \%$ macrophages, $8 \pm 1 \%$ lymphocytes, $1 \pm 1 \%$ neutrophils, $1 \pm 1 \%$ eosinophils).

Alveolar macrophages were purified from total cells obtained by lavage by adherence $\left(1 \mathrm{~h}, 37^{\circ} \mathrm{C}\right)$ to plastic culture dishes (Falcon Labware, Oxnard, CA) in Dulbecco's modified Eagle medium (DME; Whittaker Bioproducts, Walkersville, MD) supplemented with $4 \mathrm{mM}$ glutamine, $50 \mathrm{U} / \mathrm{ml}$ penicillin and $50 \mu \mathrm{g} / \mathrm{ml}$ streptomycin. The resulting macrophage populations were $>98 \%$ pure as assessed by morphology after staining with Diff-Quik (American Scientific Products, McGaw Park, IL), and were $>90 \%$ viable as estimated by trypan blue exclusion. As indicated in Results, aliquots of normal alveolar macrophages $\left(4 \times 10^{6}\right.$ cells $\left./ \mathrm{ml}\right)$ were stimulated $\left(12 \mathrm{~h}, 37^{\circ} \mathrm{C}\right)$ with $10 \mu \mathrm{g} / \mathrm{ml}$ lipopolysaccharide (LPS, Escherichia coli 0127:B8, Difco Laboratories, Detroit, MI). After incubation, the macrophages were washed with PBS, pH 7.4 and evaluated as for the unstimulated normal and IPF macrophages.

$P D G F-A$ and $-B$ probes. The PDGF-A gene probes included a 1.3kb A-chain cDNA, D1 provided by C. Betsholtz and C. Heldin (University Hospital, Uppsala, Sweden) and derivations cloned from D1 (22). The $0.24 \mathrm{~kb}$ cDNA probe pPB2 19, encompassed $103 \mathrm{bp}$ from the 3 ' end of exon I, all of exon II, and $35 \mathrm{bp}$ from the $5^{\prime}$ end of exon III. The cRNA probe was made by subcloning pPB219 into the transcription vector pBluescript SK/-(Stratagene).

The PDGF-B gene probes were derived from pPB220, a $0.9 \mathrm{~kb}$ PDGF-B cDNA cloned after reverse transcription of RNA from LPSstimulated $\left(5 \mathrm{~h}, 37^{\circ} \mathrm{C}\right)$ human blood monocytes followed by amplification of PDGF-B cDNA using the polymerase chain reaction and PDGF-B exon-specific oligonucleotide primers (23). The cDNA probe pPB220 encompassed 66 bp from the $3^{\prime}$ end of exon I, all of exons II-VI and $94 \mathrm{bp}$ from the $5^{\prime}$ end of exon VII.

As a control, a $2.3 \mathrm{~kb} \gamma$-actin cDNA pHF $\gamma \mathrm{A}-1$ was utilized (24).

Quantification of PDGF-A and -B gene transcription rates. PDGF$A$ and PDGF-B gene transcription rates were quantified by transcription "run off" $(25,26)$. Nuclei were isolated from alveolar macrophages, and incubated with [ $\left.{ }^{32} \mathrm{P}\right] \mathrm{UTP}(800 \mathrm{Ci} / \mathrm{mmol}$; Amersham Corp., Arlington Heights, IL) to label nuclear RNA. Transcription of the PDGF-A and -B genes and, as control, the $\gamma$-actin gene, was quantified by hybridization $\left(40 \mathrm{~h}, 42^{\circ} \mathrm{C}\right)$ of labeled RNA $\left(10^{7} \mathrm{cpm} / \mathrm{ml}\right)$ to excess ( $5 \mu \mathrm{g}$ ), filter-bound (nitrocellulose; Schleicher \& Schuell, Keene, NH; dot-blot apparatus, Bio-Rad Laboratories, Richmond, CA), unlabeled cDNA targets (PDGF-A: D1; PDGF-B: pPB220; and $\gamma$-actin: pHF $\gamma \mathrm{A}-1$ ) in the presence of $50 \%$ formamide and $10 \%$ dextran sulfate. Filters were then washed, subjected to autoradiography, and autoradiograms were scanned (2202 Ultrascan Laser Densitometer; Pharmacia-LKB, Piscataway, NJ). The relative transcription rates were expressed as arbitrary densitometric units.

Evaluation of PDGF-A and -B mRNA transcripts. Total cellular RNA was purified frem macrophages by the acid guanidium-thiocyanate-phenol-chloroform extraction method (27). Northern analysis was carried out using total cellular RNA for PDGF-B and $\gamma$-actin transcripts and (because preliminary studies showed it was in low abundance) poly $\mathrm{A}^{+}$RNA (obtained by oligo-dT cellulose chromatography) for PDGF-A transcripts. PDGF-B mRNA transcripts were evaluated with the PDGF-B cDNA probe pPB220, $\gamma$-actin transcripts were evaluated with the $\gamma$-actin CDNA pHF $\gamma$ A-1, and PDGF-A transcripts with the PDGF-A cDNA, D1. All probes were labeled to high specific activity with $\left[{ }^{32} \mathrm{P}\right] \mathrm{dCTP}(3000 \mathrm{Ci} / \mathrm{mmol}$, Amersham $)$ by the random hexonucleotide primer method (28).

PDGF-A, PDGF-B, and $\gamma$-actin mRNA transcripts were all quantitated in total cellular RNA with PDGF-A, PDGF-B, and $\gamma$-actin cRNA standard curves, respectively, to ensure comparability. Because of their low abundance PDGF-A mRNA transcripts were quantified in total cellular RNA using a solution hybridization/RNase protection assay (29). The ${ }^{32} \mathrm{P}$-labeled PDGF-A antisense cRNA probe was hybridized with $10 \mu \mathrm{g}$ of total cellular RNA or synthetic, unlabeled PDGF-A sense cRNA, and subjected to RNase treatment, purification, electrophoresis, and autoradiography. A standard curve was constructed using various amounts of unlabeled PDGF-A sense cRNA and the autoradiographic signals were quantified by densitometry. Because of their relative abundance, both PDGF-B and $\gamma$-actin mRNA transcripts were quantitated in macrophage total cellular RNA by dotblot analysis. Total cellular RNA (10 $\mu \mathrm{g})$ or synthetic, unlabeled PDGF-B or $\gamma$-actin cRNA was bound to nylon membranes (Schleicher \& Schuell) using a dot-blot apparatus, and hybridized with ${ }^{32} \mathrm{P}$-labeled PDGF-A CDNA probe pPB220 or the $\gamma$-actin cDNA probe pHF $\gamma$ A-1, respectively. Standard curves were constructed using various amounts of unlabeled PDGF-B cRNA $(0.31 \mathrm{~kb}$, transcribed from pPB220 and encompassed the $3^{\prime} 66$ bp of exon I, all of exons II and II and the $5^{\prime} 64$ bp of exon IV) or $\gamma$-actin sense cRNA $(0.34 \mathrm{~kb}$, prepared from a Pst I-Bgl II fragment of $\mathrm{pHF} \gamma \mathrm{A}-1$ ).

\section{Results}

PDGF gene transcription in alveolar macrophages. Normal, resting alveolar macrophages constitutively transcribed both PDGF-A and -B genes (Fig. 1). When the macrophages were stimulated with LPS, transcription rates of both genes were increased 300 to $400 \%(P<0.01$, both comparisons to unstimulated normal alveolar macrophages). Importantly, PDGF$A$ and -B gene transcription rates in alveolar macrophages from individuals with IPF were increased $300 \%$ compared with normal unstimulated alveolar macrophages $(P<0.01$,

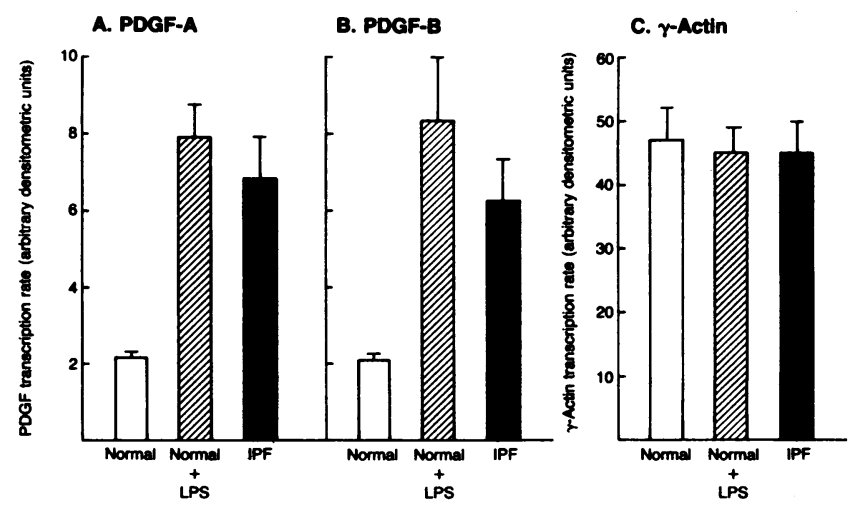

Figure 1. Rate of PDGF-A and PDGF-B gene transcription on alveolar macrophages of normals and individuals with IPF. Transcription run-off assays were carried out with nuclei isolated from normal alveolar macrophages, normal alveolar macrophages stimulated with LPS and alveolar macrophages from individuals with IPF, using $\left[{ }^{32} \mathrm{P}\right]$ UTP as the label and hybridization to nitrocellulose-bound PDGFA, PDGF-B, and $\gamma$-actin cDNAs. Shown are the results of separate experiments with four sets of individuals. The data are expressed in arbitrary densitometric units. 
both comparisons). In contrast, as a control, the transcription rate of the $\boldsymbol{\gamma}$-actin gene was not significantly different among all cell populations tested $(P>0.5)$. Because the PDGF-A and -B genes are nearly identical in size $(24 \mathrm{~kb})(9,10,15)$ and their respective cDNA targets were similar in size, and since both targets were in molar excess ( 2 pmol/dot on filter), the transcription rate determinations for both PDGF genes can be directly compared. As such, in resting normal alveolar macrophages, transcription of PDGF-A and -B genes was approximately equal. Similarly, in LPS-stimulated normal alveolar macrophages and IPF alveolar macrophages, PDGF-A and -B gene transcription rates were elevated in parallel compared to normal resting macrophages.

PDGF MRNA transcripts in alveolar macrophages. Consistent with the active transcription of PDGF-A and -B genes in resting alveolar macrophages, LPS-stimulated alveolar macrophages, and IPF alveolar macrophages, RNA recovered from alveolar macrophages of all three groups demonstrated PDGF-A and -B mRNA transcripts (Fig. 2). PDGF-A mRNA transcripts were lowest in abundance. In this regard, Northern analysis of total cellular RNA from alveolar macrophages failed to demonstrate PDGF-A transcripts, and while Northern blots made with poly A+ RNA demonstrated the expected transcripts of $2.8,2.3$, and $1.9 \mathrm{~kb}(22)$, the bands were faint (not shown). Using the more sensitive RNase protection assay, however, PDGF-A transcripts were easily detected in resting normal macrophages (Fig. 2, lane 1), and also, albeit at greater intensity, in LPS-stimulated normal alveolar macrophages (lane 2) and IPF alveolar macrophages (lane 3). In contrast to PDGF-A transcripts, Northern analysis demonstrated easily detectable PDGF-B mRNA transcripts in total cellular RNA from resting normal macrophages (lane 4) and apparently more abundant transcripts in LPS-stimulated normal (lane 5) and IPF macrophages (lane 6). Likewise, $\gamma$-actin mRNA tran-
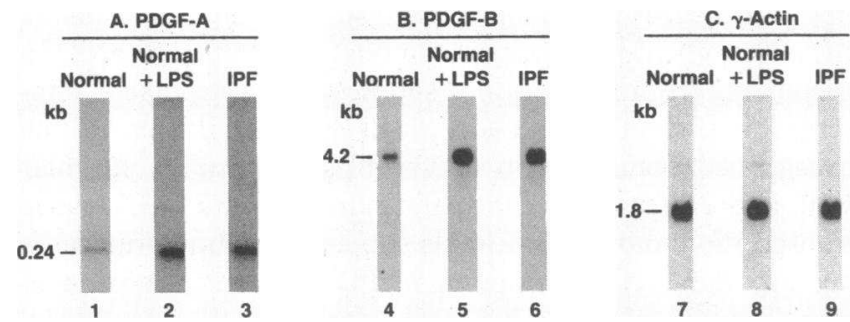

Figure 2. PDGF-A and PDGF-B mRNA transcripts in alveolar macrophages of normals and individuals with IPF. $(A)$ Solution hybridization/RNase protection analysis for PDGF-A mRNA transcripts using a ${ }^{32} \mathrm{P}$-labeled PDGF-A antisense $\mathrm{cRNA}$ probe and $10 \mu \mathrm{g}$ total cellular RNA/lane. (Lane 1) RNA from normal resting alveolar macrophages; (lane 2) normal alveolar macrophages stimulated with LPS $(10 \mu \mathrm{g} / \mathrm{ml}, 12 \mathrm{~h})$; (lane 3) IPF alveolar macrophages. The protected $0.24 \mathrm{~kb}$ PDGF-A fragment is indicated. $(B)$ Northern analysis for PDGF-B mRNA transcripts using a ${ }^{32}$ P-labeled PDGF-B cDNA probe and $10 \mu \mathrm{g}$ total cellular RNA/lane. (Lane 4) normal resting alveolar macrophages; (lane 5) normal alveolar macrophages stimulated with LPS; (lane 6) IPF alveolar macrophages. The $4.2 \mathrm{~kb}$ PDGF-B transcripts are indicated. $(C)$ Northern analysis for $\gamma$-actin mRNA transcripts using a ${ }^{32} \mathrm{P}$-labeled $\gamma$-actin cDNA probe and 10 $\mu \mathrm{g}$ total cellular RNA/lane. (Lane 7) Normal resting alveolar macrophages; (lane 8) normal alveolar macrophages stimulated with LPS; (lane 9) IPF alveolar macrophages. The $1.8 \mathrm{~kb} \gamma$-actin transcripts are indicated. The data shown is from one individual in each group and is representative of all individuals in each group. scripts were easily detectable in all three groups of macrophages, and appeared to be of similar intensity.

These qualitative observations were confirmed by direct quantification of mRNA transcript levels (Fig. 3). In this regard, IPF was associated with 4-fold increase in PDGF-A mRNA levels, as was LPS stimulation $(P<0.05$, both compared to normal; $A$ ). The same was true for PDGF-B where there was a 4-fold increase in PDGF-B mRNA levels in IPF and LPS stimulated macrophages $(P<0.05$, both comparisons to normal; $B$ ), whereas $\gamma$-actin mRNA levels were similar in all three groups $(P>0.5$, all comparisons; $C)$. Interestingly, however, in all groups, PDGF-B transcript numbers dominated, with levels 10-fold greater than PDGF-A mRNA.

\section{Discussion}

Alveolar macrophages are believed to play a central role in the pathogenesis of pulmonary fibrosis by virtue of their ability, when activated, to release a variety of polypeptide mediators that act as chemoattractants and mitogens for fibroblasts (see Reference 1 for review). The most potent of these polypeptides is PDGF, a molecule capable of functioning in the picomolar range (5-7). Direct evidence for a role of PDGF in the pathogenesis of pulmonary fibrosis comes from the observation that alveolar macrophages recovered from the lungs of individuals with idiopathic pulmonary fibrosis are spontaneously releasing approximately 0.7 pmol PDGF $/ 10^{6}$ alveolar macrophages, a level fourfold above that of normal resting alveolar macrophages, and comparable to the amount of PDGF released by alveolar macrophages activated in vitro by inflammatory stimuli (8). Furthermore, it is known that fibroblasts normally express PDGF receptors and respond to exogenous PDGF by proliferating $(5,7)$. A caveat is that there is no direct evidence that the proliferating fibroblasts observed in the lungs of indi-
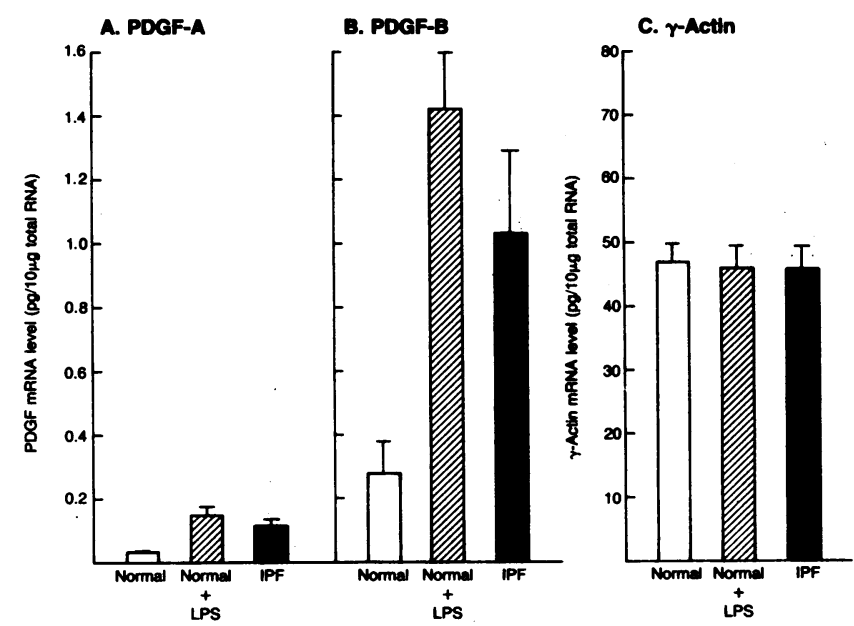

Figure 3. Quantification of PDGF-A and PDGF-B and mRNA transcript levels in alveolar macrophages from normals and individuals with IPF. Total cellular RNA (10 $\mu \mathrm{g})$ from normal resting alveolar macrophages $(n=8)$, normal alveolar macrophages stimulated with LPS $(n=8)$ and alveolar macrophages from individuals with IPF ( $n$ $=10$ ) was evaluated for PDGF-A, PDGF-B, and $\gamma$-actin mRNA. $(A)$ PDGF-A mRNA transcript levels quantitated by RNase protection analysis. (B) PDGF-B mRNA levels quantitated by dot-blot analysis. (C) $\gamma$-actin mRNA levels quantitated by dot-blot analysis. 
viduals with IPF have retained their PDGF receptors and are responding directly to the increased burden of PDGF seen in this disorder. Importantly, however, the present study demonstrates that alveolar macrophages of individuals with IPF are actively transcribing both the PDGF-A and PDGF-B genes at rates higher than normal, and in a fashion similar to that of normal alveolar macrophages activated in vitro with a surface inflammatory stimulus. These observations are consistent with the concept that the disease is driven by processes external to the inflammatory cells, but mediated through the upregulation of normal pathways. In support of this, quantitation of PDGF-A and PDGF-B mRNA transcripts in IPF macrophages demonstrated that both were markedly increased compared to resting macrophages, in a pattern similar to that observed in normal alveolar macrophages activated in vitro. Importantly, PDGF-B transcript numbers in IPF alveolar macrophages dominated the PDGF-A transcript numbers by a ratio of 10 to 1 , suggesting that the PDGF produced by the alveolar macrophages in the disease are likely B-B homodimers, among the most potent of the known PDGF molecules.

The observation that alveolar macrophages from individuals with IPF have upregulated the PDGF-B gene, and have significantly increased numbers of PDGF-B mRNA transcripts is of interest in the context of the knowledge that the PDGF-B gene is the $c$-sis gene, the human analog of the v-sis oncogene, the transforming gene of the simian sarcoma virus (16-18). While it is known that the levels of PDGF-B mRNA transcripts are high in transformed and tumor derived cell lines (14), and it is known that certain classes of normal cells are capable of upregulating the PDGF-B gene (30), to our knowledge, this is the first demonstration of the in vivo upregulation of transcription of the PDGF-B gene in nonneoplasic cells in humans. While the specific stimulus responsible for turning on this gene in alveolar macrophages in IPF is not known, the observation that IPF alveolar macrophages are transcribing the gene at a rate higher than normal blurs the distinction between fibrosis and neoplasia, and supports the concept that these two general categories of disease likely utilize similar classes of genes in modulating the enhanced proliferation of the cell types characteristic of each disorder.

Although there is clear evidence that IPF alveolar macrophages are spontaneously releasing exaggerated amounts of PDGF molecules (8), the composition of these molecules is unknown. The size of the mature protein products predicted from the open reading frames of the two PDGF cDNA transcripts are $14.3 \mathrm{kDA}$ (PDGF-A) and $12.3 \mathrm{kDA}$ (PDGF-B) (5-7). The intact, mature $30 \mathrm{kDA}$ PDGF molecules consist of two disulfide-linked chains of A-B heterodimers, A-A homodimers, or B-B homodimers; all of these forms have been observed to be produced normally in vivo (A-B heterodimers) or by various normal and neoplastic cells in culture (A-A and B-B homodimers) $(5-7,22,31,32)$. Knowledge of the form of PDGF being produced by alveolar macrophages in IPF is relevant in the context of evidence that B-B homodimers and A-B heterodimers both have potent chemoattractant and mitogenic activities (5-7, 33, 34). In contrast, the PDGF molecule composed of A-A homodimers does not serve as a chemoattractant and is only weakly mitogenic $(7,33,34)$. Analysis of the type of PDGF being released by the alveolar macrophages in IPF is very difficult at the protein level because of the relatively small numbers of cells that can be obtained from these individuals. It is known, however, that the PDGF released by
IPF alveolar macrophages functions both as a growth signal for fibroblasts, and a chemoattractant for smooth muscle cells, properties suggesting it is comprised of A-B heterodimers and/ or B-B homodimers. This concept is supported by the observation that the IPF macrophages contain 10 -fold more PDGF-B gene mRNA transcripts than PDGF-A transcripts. Thus, while it is conceivable that the $B$ transcripts are not functional, it is likely that the major PDGF product of IPF alveolar macrophages are B-B homodimers.

The fact that both the IPF alveolar macrophages and the LPS stimulated normal alveolar macrophages have increased levels of A and B transcripts is consistent with the fact that the transcription of both genes is increased in these macrophages. However, the fact that both IPF and LPS stimulated macrophages have 10-fold more PDGF-B transcripts than PDGF-A transcripts is of interest in the context that in both circumstances there is approximately equal (albeit increased compared to normal resting macrophages) transcription rates for both the PDGF-B and PDGF-A genes. This observation is unexpected and suggests that PDGF-B and -A gene expression is differentially regulated at the level of mRNA accumulation. The actual mechanism(s) by which PDGF-A mRNA levels are selectively reduced compared to PDGF-B mRNA levels in alveolar macrophages is not known. Unfortunately, the limited number of alveolar macrophages available precludes further analysis of this dichotomy using presently available methods.

In the context of the central role of the alveolar macrophage in the pathogenesis of IPF (1), and the likelihood that B-B homodimers are the form of PDGF being released in this disease, the observation that the PDGF-B gene is upregulated in IPF macrophages similar to that of activated normal macrophages has therapeutic implications for this disorder. Although a causal relationship has not been definitively established, the increased alveolar macrophage PDGF gene expression seen at all levels and the increased alveolar fibroblast proliferation observed in IPF patients provide a specific target to evaluate the effect of various therapeutic modalities. In this regard, if a therapeutic regimen does not suppress the upregulated transcription of the PDGF-B gene, it likely will not suppress the exaggerated accumulation of fibroblasts within the alveolar walls in the disease. Also, the parallel increase in PDGF-B gene transcription and mRNA levels suggests that transcription is an important regulatory point in PDGF gene expression in alveolar macrophages. This suggests that one therapeutic target for this disease might aim at downregulating alveolar macrophage PDGF-B gene transcription and mRNA accumulation. For example, this might be accomplished by transferring an artificial antisense (35) PDGF gene driven by the normal PDGF-B gene promoter into alveolar macrophages of these individuals, resulting in the suppression of the burden of this potent chemotactic and mitogenic signal in the lungs.

\section{Acknowledgments}

We thank P. Gunning and L. Kedes, Stanford University for providing the $\gamma$-actin cDNA pHF $\gamma \mathrm{A}-1$, and C. Betsholtz and C. H. Heldin, University Hospital, Uppsala, Sweden for providing the PDGF-A cDNA, D1.

\section{References}

1. Crystal, R. G., P. B. Bitterman, S. I. Rennard, A. J. Hance, and B. A. Keogh. 1984. Interstitial lung diseases of unknown cause. Dis- 
orders characterized by chronic inflammation of the lower respiratory tract. N. Engl. J. Med. 310:154-156, 235-244.

2. Agelli, M., and S. M. Wahl. 1986. Cytokines and fibrosis. Clin. Exp. Immunol. 4:379-388.

3. Shimokado, K., E. W. Raines, D. K. Madtes, T. B. Barrett, E. P. Benditt, and R. Ross. 1985. A significant part of marcophage-derived growth factor consists of at least two forms of PDGF. Cell. 43:277-286.

4. Martinet, Y., P. B, Bitterman, J.-F. Mornex, G. R. Grotendorst, G. R. Martin, and R. G. Crystal. 1986. Activated human monocytes express the c-sis proto-oncogene and release a mediator showing PDGF-like activity. Nature (Lond.). 319:158-160.

5. Ross, R., E. W. Raines, and D. F. Bowen-Pope. 1986. The biology of platelet-derived growth factor. Cell. 46:155-169.

6. Ross, R. 1989. Peptide regulatory factors. Platelet-derived growth factor. Lancet. i:1179-1182.

7. Heldin, C. F., and B. Westermark. 1989. Platelet-derived growth factor: three isoforms and two receptor types. Trends Genet. 5:108111.

8. Martinet, Y., W. R. Rom, G. R. Grothendorst, G. R. Martin, and R. G. Crystal. 1987. Exaggerated spontaneous release of plateletderived growth factor by alveolar macrophages from patients with idiopathic pulmonary fibrosis. N. Engl. J. Med. 317:202-209.

9. Rorsman, F., M. Bywater, T. J. Knott, J. Scott, and C. Betsholtz. 1988. Structural characterization of the human platelet-derived growth factor A-chain cDNA and gene: alternative exon usage predicts two different precursor proteins. Mol. Cell. Biol. 8:571-577.

10. Bonthron, D. T., C. C. Morton, S. H. Orkin, and T. Collins. 1988. Platelet-derived growth factor A chain: gene structure, chromosomal location, and basis for alternative mRNA splicing. Proc. Natl. Acad. Sci. USA. 85:1492-1496.

11. Tong, B. D., D. E. Auer, M. Jaye, J. M. Kaplow, G. Ricca, E. McConathy, W. Drohan, and T. F. Deuel. 1987. cDNA clones reveal differences between human glial and endothial cell platelet-derived growth factor A-chains. Nature (Lond.). 328:619-621.

12. Collins, T., D. T. Bonthron, and S. H. Orkin. 1987. Alternative RNA splicing affects function of encoded platelet-derived growth factor A chain. Nature (Lond.). 328:621-624.

13. Bartram, C. R., A. de Klein, A. Hagemeijer, G. Grosveld, N. Heisterkamp, and J. Groffen. 1984. Localization of the human c-sis oncogene in $\mathrm{Ph}^{1}$-positive and $\mathrm{Ph}^{1}$-negative chronic myelocytic leukemia by in situ hybridization. Blood. 63:223-225.

14. Collins, T., D. Ginsburg, J. M. Boss, S. H. Orkin, and J. S. Pober. 1985. Cultured human endothelial cells express platelet-derived growth factor B chain: cDNA cloning and structural analysis. Nature (Lond.). 316:748-750.

15. Rao, C. D., H. Igarashi, I. M. Chiu, K. C. Robbins, and S. A. Aaronson. 1986. Structure and sequence of the human c-sis/plateletderived growth factor 2 (SIS/PDGF2) transcriptional unit. Proc. Natl. Acad. Sci. USA. 83:2392-2396.

16. Waterfield, M. D., G. T. Scrace, N. Whittle, P. Stroobant, A. Johnsson, A. Wasteson, B. Westermak, C. H. Heldin, J. S. Huang, and T. F. Deuel. 1983. Platelet-derived growth factor is structurally related to the putative transforming protein $\mathbf{p} 28^{\mathrm{sis}}$ of simian sarcoma virus. Nature (Lond.). 304:35-39.

17. Doolittle, R. F., M. W. Hunkapiller, L. E. Hood, S. G. Devare, K. C. Robbins, S. A. Aaronson, and H. N. Antoiades. 1983. Simian sarcoma virus onc gene, v-sis, is derived from the gene (or genes) encoding a platelet-derived growth factor. Science (Wash. DC). 21:275-277.

18. Pech, M., Gazit, P. Aarnstein, and S. A. Aaronson. 1989. Generation of fibrosarcomas in vivo by a retrovirus that expresses the normal $B$ chain of platelet-derived growth factor and mimics the alternative splice pattern of the v-sis oncogene. Cell Biol. 86:2693-2697.

19. Mornex, J. F., Y. Martinet, K. Yamauchi, P. B. Bitterman, G. R. Grotendorst, A. Chytil-Wier, G. R. Martin, and R. G. Crystal.
1986. Spontaneous expression of the c-sis gene and release of a platelet-derived growth factor-like molecule by human alveolar macrophages. J. Clin. Invest. 78:61-66.

20. Fulmer, J. D., W. C. Roberts, E. R. Von Gal, and R. G. Crystal. 1977. Small airways in idiopathic pulmonary fibrosis. Comparison of morphologic and physiologic observations. J. Clin. Invest. 60:595610.

21. Saltini, C., A. J. Hance, V. J. Ferrans, F. Basset, P. B. Bitterman, and R. G. Crystal. 1984. Accurate quantification of cells recovered by bronchoalveolar lavage. Am. Rev. Respir. Dis. 130:650-658.

22. Betsholtz, C., A. Johnsson, C.-H. Heldin, B. Westermark, P. Lind, M. S. Urdea, R. Eddy, T. B. Shows, K. Philpott, A. L. Mellor, T. J. Knott, and J. Scott. 1986. cDNA sequence and chromosonal localization of human platelet-derived growth factor A-chain and its expression in tumor cell lines. Nature (Lond.). 320:695-699.

23. Saiki, R. K., D. H. Gelfand, S. Stoffel, S. J. Scharf, R. Higuchi, G. T. Horn, K. B. Mullis, and H. A. Erlich. 1988. Primer-directed enzymatic amplification of DNA with a thermostable DNA polymerase. Science (Wash. DC). 239:487-491.

24. Gunning P., P. Ponte, H. Okayama, J. Engel, H. Blau, and L. Kedes. 1983. Isolation and characterization of full-length cDNA Clones for human $\alpha-, \beta$-, and $\gamma$-Actin mRNAs: skeletal but not cytoplasmic actins have an amino-terminal cysteine that is subsequently removed. Mol. Cell. Biol. 3:787-795.

25. Groudine, M., M. Peretz, and H. Weintraub. 1981. Transcriptional regulation of hemoglobin switching in chicken embryos. $\mathrm{Mol}$. Cell. Biol. 1:281-288.

26. Mitchell, R. L., C. Henning-Chubb, E. Huberman, and I. M. Verma. 1986. c-fos expression is neither sufficient nor obligatory for differentiation of monomyelocytes to macrophages. Cell. 45:497-504.

27. Chomczynski, P., and N. Sacchi. 1987. Single-step method of RNA isolation by acid guanidinium thiocynate-phenol-chloroform extraction. Anal. Biochem. 162:156-159.

28. Feinberg, A. P., and B. Vogelstein. 1983. A technique for radiolabeling DNA restriction endonuclease fragments to high specific activity. Anal. Biochem. 132:6-13.

29. Rom, W. N., P. Bassett, G. A. Fells, T. Nukiwa, B. C. Trapnell, and R. G. Crystal. 1988. Alveolar macrophages release an insulin-like growth factor I-type molecule. J. Clin. Invest. 82:1685-1693.

30. Kavanaugh, W. M., G. R. Harsh IV, N. F. Starksen, C. M. Rocco, and L. T. Williams. 1988. Transcriptional regulation of the A and B chain genes of platelet-derived growth factor in microvascular endothelial cells. J. Biol. Chem. 263:8470-8472.

31. Sejersen, T., C. Betsholtz, M. Sjolund, C.-H. Heldin, B. Westermark, and J. Thyberg. Rat skeletal myoblasts and arterial smooth muscle cells express the gene for the A chain but not the gene for the B gene chain (c-sis) of platelet-derived growth factor (PDGF) and produce a PDGF-like protein. Proc. Natl. Acad. Sci. USA. 83:6844-6848.

32. Collins, T., J. S. Pober, M. A. Gimbrone, Jr., A. Hammacher, C. Betsholtz, B. Westermark, and C.-H. Heldin. 1987. Cultured human endothelial cells express platelet-derived growth factor A chain. Am. J. Pathol. 127:7-12.

13. Heldin, C.-H., G. Backstrom, A. Ostman, A. Rubin, M. Nister, and B. Westermark. 1988. Binding of different dimeric forms of PDGF to human fibroblasts: evidence for two separate receptor types. $E M B O$ (Eur. Mol. Biol. Organ.) J. 7:1387-1393.

34. Nister, M., A. Hammacher, K. Mellstrom, A. Siegbahn, L. Ronnstrand, B. Westermark, and C.-H. Heldin. 1988. A glioma-derived PDGF A chain homodimer has different functional activities from a PDGF AB heterodimer purified from human platelets. Cell. 52:791-799.

35. van der Krol, A. R., J. N. M. Mol, and A. R. Stuitje. 1988. Modulation of eukaryotic gene expression by complimentary RNA or DNA sequences. Biotechnology. 6:958-976. 